Annals of Plant and Soil Research 23(2): 164-169 (2021)

https://doi.org/10.47815/apsr.2021.10050

\title{
Preventive measures against contamination of vegetables by endophytic Salmonella sp. with antibacterial property of Ocimum basilicum $L$.
}

\author{
HIRAL S. RAVAL* AND ALKESH I. SHAH \\ Department of Biology, B.P. Baria Science Institute, Veer Narmad South Gujarat University, Navsari,396445, \\ Gujarat, India
}

Received: February, 2021; Revised accepted: March, 2021

\begin{abstract}
Spinach samples $(n=120)$ were collected from various zones of Surat city, Gujarat from December 2018 to November 2019. The accumulated samples were investigated (ISO 6579-1:2017 E) for endophytic contamination of Salmonella sp. From 120 collected samples 16 samples (\% prevalence=13.3) were found positive for the endophytic Salmonella $s p$. which is a significant sign of vegetable contamination with this pathogenic bacteria. Lab-scale, pot, and field experiments were conducted on soil treatment from January 2018 to November 2020 to study the antibacterial effect of Ocimum basilicum (OB) using different concentrations of methanolic $O B$ extracts(3.90,7.81,15.62,31.25, 62.5, 125, 250, and $500 \mu \mathrm{l} / \mathrm{mL})$ with spinach as test crop. The experiment was constructed in an absolute randomized design with three repetitions. Results revealed that the plant was prevented from endophytic Salmonella sp. contamination on the treatment of soil by application of MIC concentration of $O B$ extract, which was determined $125 \mathrm{~mL} \mathrm{~L}^{-1} \mathrm{~kg}^{-1}$. Application of OB extract had significantly prevented the contamination of endophytic Salmonella sp. Growth curve studies of endophytic Salmonella isolates were carried out with treated and untreated soil, which showed significant control and prevention of Salmonella sp. on treatment with OB extracts at MIC. Thus, results suggested that application of MIC $125 \mathrm{~mL} \mathrm{~L}^{-1} \mathrm{~kg}^{-1}$ of OB extract proved Ocimum basilicum L. (OB) can efficaciously prevent endophytic contamination of Salmonella sp. and have an antibacterial effect on Salmonella sp.
\end{abstract}

Keywords: Antibacterial, endophytic, biofilm, prevention, MIC, MBC, Ocimum

\section{INTRODUCTION}

The O.basilicum L. extracts revealed an extensive and varying range of chemical compounds, depending on distinctions in chemotypes, leaf-flower colors, aroma, and origin of the plants. The chemical constituents showed the existence of monoterpene hydrocarbons, oxygenated sesquiterpene, flavonoids, oxygenated monoterpene, sesquiterpene hydrocarbons, triterpene, aromatic compounds, etc. The composites have been testified to demonstrate antimicrobial (Bassolé et al., 2010), antifungal, antioxidant (Politeo. et al. 2007), antibacterial (WannissornB. Et al. 2005), antiviral, and insecticidal activities. The major constituents include chavicol, estragole (Hassanpouraghdam, et al. 2010), linalool, and eugenol (Hussain et al., 2008). Abundant analysis has explored the probable risks of contamination in the vegetables during precultivation and post-cultivation stages. Throughout the stages, risky inhabitants can inaugurate their habitat and get nurtured on cultivating yield. The hazard was competently increased within consequent yield whichever through promoting straight contamination or through the proliferation of surviving harmful inhabitants throughout handling and postcultivation controlling measures (Zheng, et al. 2013). The principal origin of contamination in the zone is mostly noticed to be water and soil. Predictably, plants are not envisioned as hosts Salmonella $s p$; these bacteria repeatedly concomitant among mammalian or further animal hosts. Furthermore, the latest outcomes have also revealed that Salmonella $s p$. colonize upon the exterior and innermost parts of the plants in equivalently epiphytic and endophytic survival, consistently (Kisluk and Yaron 2012). Additionally, to withstand severe environmental surroundings, it is recommended that Salmonella sp. could spread to the interior tissues of the plants to upgrade an effective defense versus harsh surroundings existing on the plant exterior and thus attain or improve competencies to colonize in plants and improve

*Corresponding author, Email: hiralraval31@gmail.com, Mobile: +919099171454 
resistance to antimicrobial actions (Schikora et al. 2008). This provokes several sirens concerning the appliance, phenotypic behaviors, and virulence of Salmonella sp. concomitant with the non-animal accommodate i.e. plant. The present study was conducted to study the efficiency of preventive measures on-field application for preventing endophytic contamination of Salmonella sp. to the crop plants by treating the soil with eco-friendly herbal composition from Ocimum basilicum L. without affecting soil fertility.

\section{MATERIALS AND METHODS}

A total of 120 spinach (D) samples were collected from December 2018 to November 2019 from the regional vegetable market of the Surat city (Katargam, Varachha, Amroli, Limbayat, Adajan, Bhatar). The individual vegetable sample was kept in an individual sterile plastic zipper bag and endophytic strains of Salmonella sp. were acquired from the fragments of the exterior-sterilized raw salad vegetable samples. Detection and isolation were done with the help of the ISO 6579-1:2017 E method. Pathogenicity and antibiotic susceptibility assay was carried out from all the sixteen isolates (DP1 to DP16), and it was observed that five isolates from sixteen isolates showed the most pathogenic characteristics along with drug resistance and were selected for further studies. Fresh leaves of Ocimum basilicum L.(OB) were cleaned with tap water, shade-dried, and extracted using the soxhlet extraction method successively in methanol as a solvent. The extract suspensions were filtered through Whatman filter paper No. 1. Filtrates were then concentrated under reduced pressure at $35^{\circ} \mathrm{C}-40^{\circ} \mathrm{C}$ using a rotary evaporator to yield the residues of different extracts. The remaining solid was denoted as the crude extract and its percentage yield was calculated.

\section{Weight of crude extract obtained in gm Percentage Yield $=\mathrm{X} 100$ \\ Total weight of dried plant material in gm \\ Stocks solutions of extracts in dimethylsulphoxide (DMSO) $(10.0 \% \mathrm{v} / \mathrm{v})$ were prepared and stored at $4^{\circ} \mathrm{C}$ for further experiments.}

\section{Antibacterial activity of $O B$ plant extract}

In vitro determination of $M I C$ and $M B C$ :

The antibacterial activity of the methanolic extract was investigated using the agar well diffusion method. The minimum inhibitory concentration (MIC) and minimum bactericidal concentration(MBC) of methanolic extract were determined using the Resazurinbased microtitre two-fold serial dilution method. A growth curve study was also done for confirming the antibacterial activity of $O B$ plant extract. Bacterial growth was determined at every one-hour interval up to $10 \mathrm{~h}$ with the help of a UV-visible spectrophotometer. SPSS software was used to statistically analyse the data.

Antibacterial effect study of soil treatment with MIC of $O B$ extract in pot and field cultivation: Detected MIC ( $125 \mathrm{~mL} / \mathrm{L})$ of $\mathrm{OB}$ extract was prepared on large scale and two sets of the pot $(20 \mathrm{~cm} \mathrm{X} 40 \mathrm{~cm}$ each) for each isolate was prepared with and without $\mathrm{OB}$ extract, bacterial culture from isolates (DP1, DP3, DP7, DP11, DP16) were prepared according to McFarland turbidity Standard (Dastouri et al., 2008) and inoculated in the soil of both the sets and observed for antibacterial effect and growth of spinach for 8 weeks. Periodically a soil, water, and spinach leave sample from each pot and spinach leaf sample was analysed for contamination of Salmonella sp. by ISO 6579-1:2017 E method.

Based on pot cultivation isolate DP3 was found more sensitive against MIC (125 mL/ L) of $\mathrm{OB}$ extract and was selected for field cultivation study. The field was selected in two plot sets (each $2 \times 2 \mathrm{~m}^{2}$ plot, 100 plants plot $^{-1}$ ), set one prepared with $\mathrm{OB}$ extract, and set two was prepared without OB extract. After treatment of soil periodically soil, water, and spinach leaf samples from fields were analysed for contamination of Salmonella sp. by ISO 65791:2017 $\mathrm{E}$ method. The data were statistically analyzed to determine significant treatment differences. In vitro evaluation of the antibacterial activity of $\mathrm{OB}$ extract against Salmonella isolates was conducted in the B.P.Baria science institute, Navsari, Gujarat. and field experiment was laid out in a randomized private plot at Variav, Surat in 2018-2020. 


\section{RESULTS AND DISCUSSION:}

\section{Prevalence of Salmonella sp :}

Out of 120 collected spinach samples from different regions of Surat, 16 samples were found positive (Table 1) for Salmonella sp. and is confirmed with biochemical tests and molecular analysis. Overall $13.3 \%$ prevalence was determined and the Amroli region of Surat showed the highest \% prevalence whereas Varachha, Limbayat, and Dindoli showed the lowest $(1.66 \%)$ prevalence of endophytic Salmonella sp. contamination. Similar results for surface inhabitants were reported by Mritunjay . et al. (2017). Out of all 16 Salmonella $s p$. Isolates, 4 isolates were typhoidal and the remaining 12 were nontyphoidal. Based on the results of pathogenicity tests it was observed that five isolates were most pathogenic and resistant to the most antibiotic drug. Fifteen drugs were tested for antimicrobial sensitivity out of which resistance for nine drugs was exhibited by isolate DP3. Whereas DP1 isolates showed drug resistance for seven drugs. Based on pathogenicity assays it was found that out of all isolates DP3 was most pathogenic as they showed strong biofilm production, hemolysin production, salt aggregation, crystal violate binding, autoagglutination, swarming, EPS production, congo-red assay, and most drugresistant, so DP3 isolates were selected for labscale, pot, and field cultivation experiments. OB extracts were prepared in methanol solvents. The percentage yield of these crude extract was $36.2 \% \mathrm{w} / \mathrm{w}$.

Table: 1 Location-wise \% prevalence of Salmonella sp.

\begin{tabular}{c|c|c|c|c|}
\hline Location & $\begin{array}{c}\text { Total spinach sample } \\
\text { collected }\end{array}$ & $\begin{array}{c}\text { Number of } \\
\text { Salmonella sp. isolates }\end{array}$ & $\begin{array}{c}\text { \% Prevalence* of } \\
\text { Salmonella sp. }\end{array}$ & Isolates labeled as \\
\hline Katargam & 20 & 3 & 2.5 & DP1-DP3 \\
Varachha & 20 & 2 & 1.66 & DP4-DP5 \\
Amroli & 20 & 4 & 3.33 & DP6-DP9 \\
Adajan & 20 & 3 & 2.5 & DP10-DP12 \\
Limbayat & 20 & 2 & 1.66 & DP13-DP14 \\
Dindoli & 20 & 2 & 1.66 & DP15-DP16 \\
TOTAL & $\mathrm{N}=120$ & 16 & 13.33 & DP1-DP16 \\
\hline
\end{tabular}

*\% prevalence $=($ total number of isolates $/$ total number of samples analysed $) \times 100$

Antibacterial activity of $O B$ plant extract In vitro analysis:

The zone of inhibition ( $\mathrm{ZI})$ of various $\mathrm{OB}$ extract aliquots and ampicillin against 5 bacterial isolates were recorded at different concentrations. The various calculated $\mathrm{ZI}$ of all the $\mathrm{OB}$ extracts dilution ranges from $12.2 \pm 0.1$ $\mathrm{mm}$ to $26.1 \pm 0.4 \mathrm{~mm}$ (Table 2 ).

Table: 2 Agar well diffusion assay zone of inhibition

\begin{tabular}{|c|c|c|c|c|c|c|}
\hline \multirow{2}{*}{$\begin{array}{c}\text { Dilution } \\
\mu \mathrm{l} / \mathrm{mL}\end{array}$} & \multicolumn{5}{|c|}{ OB extract ZI $(\mathrm{mm} \pm \mathrm{SD})$} & Ampicillin ZI (mm \pm \\
\cline { 2 - 6 } & DP1 & DP3 & DP7 & DP11 & DP16 & SD) STANDARD \\
\hline 20 & $14.2 \pm 0.1$ & $18.2 \pm 0.1$ & $12.2 \pm 0.1$ & $14.6 \pm 0.1$ & $16.2 \pm 0.1$ & $16.1 \pm 0.1$ \\
40 & $14.6 \pm 0.4$ & $18.6 \pm 0.4$ & $12.6 \pm 0.4$ & $18.2 \pm 0.4$ & $16.6 \pm 0.4$ & $18.1 \pm 0.1$ \\
80 & $16.1 \pm 0.2$ & $18.8 \pm 0.2$ & $14.8 \pm 0.2$ & $18.7 \pm 0.2$ & $16.8 \pm 0.2$ & $20.4 \pm 0.2$ \\
100 & $16.3 \pm 0.4$ & $20.2 \pm 0.4$ & $16.2 \pm 0.4$ & $18.8 \pm 0.4$ & $18.2 \pm 0.4$ & $22.4 \pm 0.4$ \\
500 & $16.6 \pm 0.4$ & $26.1 \pm 0.4$ & $20.1 \pm 0.4$ & $22.1 \pm 0.4$ & $21.1 \pm 0.4$ & $24.6 \pm 0.6$ \\
\hline
\end{tabular}

${ }^{\star} \mathrm{ZI}=$ zone of inhibition

Similar results were reported by Rattanachaikunsopon P. et. al. (2010). DP3 isolates showed the highest zone size $26.1 \pm$ $0.4 \mathrm{~mm}$ for aliquotes $500 \mu \mathrm{l} / \mathrm{ml}$ whereas DP7 isolates showed lowest zone size $16.6 \pm 0.4 \mathrm{~mm}$ for aliquotes $500 \mu \mathrm{l} / \mathrm{ml}$. DP3 isolates showed significant zone size $18.2 \pm 0.1 \mathrm{~mm}$ observed for lowest dilution was $20 \mu \mathrm{l} / \mathrm{ml}$. Al-Hadidy Y. I. et. al.(2019) had reported similar results for Salmonella sp. against Eucalyptus 
camaldulensis essential oil. Out of all five isolates, DP3 showed strong sensitivity against $\mathrm{OB}$ extract at all dilutions whereas other isolates showed mild to moderate sensitivity similar results were reported by Mostafa, A.A et.al. (2018). According to Resazurin-based micro serial dilution crude OB extract, the highest antibacterial activity against DP3 isolates with MIC value of $125 \mu \mathrm{l} / \mathrm{ml}$ and MBC value $250 \mu \mathrm{l} / \mathrm{ml}$ was observed(Table3). Whereas lowest activity was observed against DP16 isolate with MIC value of $500 \mu \mathrm{l} / \mathrm{ml}$. Based on the comparison of MIC values of OB extract dilutions DP3 isolate was selected for pot and field cultivation experiments. These results indicated that $\mathrm{OB}$ extract can inhibit bacterial growth without bactericidal activity as the MIC value is lower than the MBC value.

Table : 3 Resazurin based micro-titre MIC assay

\begin{tabular}{cccccccccc|c|}
\hline ISOLATES & $500 \mu \mathrm{l} / \mathrm{mL}$ & $250 \mu \mathrm{l} / \mathrm{mL}$ & $125 \mu \mathrm{l} / \mathrm{mL}$ & $62.5 \mu \mathrm{l} / \mathrm{mL}$ & $31.25 \mu \mathrm{l} / \mathrm{mL}$ & $15.62 \mu \mathrm{l} / \mathrm{mL}$ & $7.81 \mu \mathrm{l} / \mathrm{mL}$ & $3.90 \mu \mathrm{l} / \mathrm{mL}$ \\
\hline DP1 & NG & $\mathrm{NG}$ & $\mathrm{G}$ & $\mathrm{G}$ & $\mathrm{G}$ & $\mathrm{G}$ & $\mathrm{G}$ & $\mathrm{G}$ \\
DP3 & NG & NG & NG & $\mathrm{G}$ & $\mathrm{G}$ & $\mathrm{G}$ & $\mathrm{G}$ & $\mathrm{G}$ \\
DP7 & NG & $\mathrm{G}$ & $\mathrm{G}$ & $\mathrm{G}$ & $\mathrm{G}$ & $\mathrm{G}$ & $\mathrm{G}$ & $\mathrm{G}$ \\
DP11 & NG & NG & $\mathrm{G}$ & $\mathrm{G}$ & $\mathrm{G}$ & $\mathrm{G}$ & $\mathrm{G}$ & $\mathrm{G}$ \\
DP16 & $\mathrm{NG}$ & $\mathrm{G}$ & $\mathrm{G}$ & $\mathrm{G}$ & $\mathrm{G}$ & $\mathrm{G}$ & $\mathrm{G}$ & $\mathrm{G}$ \\
\hline
\end{tabular}

${ }^{\star} G=$ Growth (pink colour), ${ }^{* *} N G=$ No growth(blue colour)

Growth curve analysis with MIC:

This study showed that treatment with MIC of OB Extract can successfully inhibit the growth of different Salmonella sp. isolates. Out of all five isolates, DP3 showed more sensitivity against OB extract when treated with MIC (125 $\mu \mathrm{l} / \mathrm{mL}$ ) (Figure: 1) and is selected for further studies. Similar results were reported for Citrus hystrix against Salmonella sp. by Maulidah, E. et. al (2021). Growth curve pattern showed DP3 growth was inhibited without bactericidal activity with MIC concentration of $\mathrm{OB}$ extract and can not form biofilm components in presence of $O B$ extract when assayed for crystal violate binding assay, whereas other isolates prevented from growth but they did not found to be prevented from biofilm production when treated with MIC of $\mathrm{OB}$ extracts. These results indicate there is a significant growth inhibitory effect of OB extract on all the isolates. Out of all isolates, DP3 showed the highest inhibitory effect against $O B$ extract.

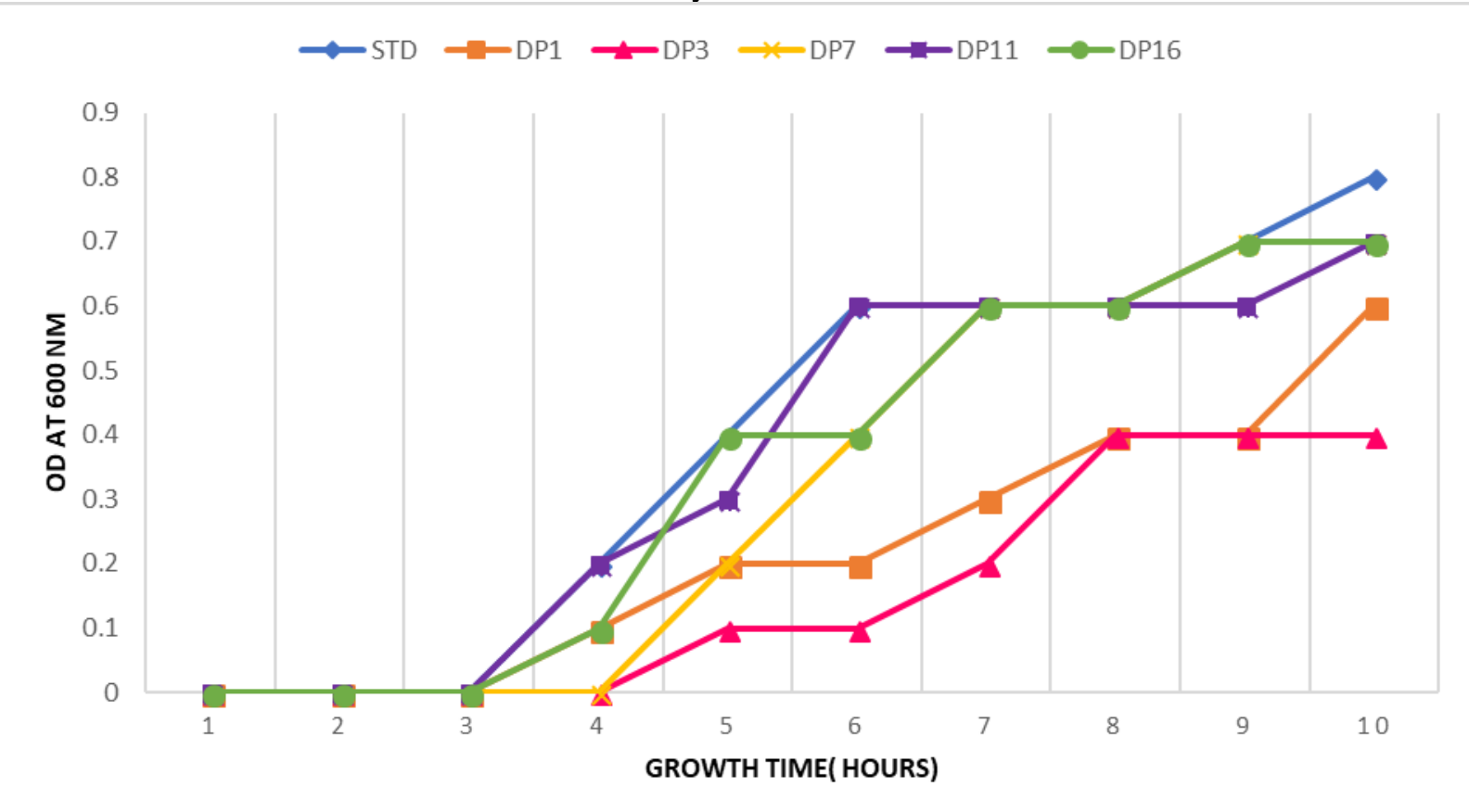

Figure 1: Growth curve study of Salmonella sp. with MIC of OB extract 
Antibacterial effect study with MIC of $O B$ extract in pot and field cultivation

On the treatment of soil with MIC concentration of $\mathrm{OB}$ extract to set - 1, it was observed that Salmonella sp. can not contaminate spinach plant in presence of $\mathrm{OB}$ extract. Periodically, on each $14^{\text {th }}$ day three random samples of soil, water, and spinach leaf were collected from both sets and were analysed for contamination of Salmonella sp. for subsequent 56 days. From set- 2 viable Salmonella $s p$. was recovered from soil and spinach leaves both, whereas from set- 1 viable Salmonella $s p$. was recovered only from soil, which was treated with MIC of OB extract (Table 4).

Table: 4 Antibacterial effect study of MIC of OB extract on pot and field cultivation

\begin{tabular}{|c|c|c|c|c|c|c|c|c|}
\hline \multirow{3}{*}{$\begin{array}{l}\text { Periodic } \\
\text { bacterial } \\
\text { detection }\end{array}$} & \multicolumn{4}{|c|}{ Pot experiment } & \multicolumn{4}{|c|}{ Field experiment } \\
\hline & \multicolumn{2}{|c|}{ SET -1 } & \multicolumn{2}{|c|}{ SET- 2} & \multicolumn{2}{|c|}{ PLOT-1 } & \multicolumn{2}{|c|}{ PLOT -2 } \\
\hline & $\begin{array}{l}\text { Soil treated } \\
\text { with MIC of } \\
\text { OB Extract }\end{array}$ & $\begin{array}{l}\text { Harvested } \\
\text { spinach } \\
\text { leaves }\end{array}$ & $\begin{array}{c}\text { Soil } \\
\text { without } \\
\text { treatment }\end{array}$ & $\begin{array}{c}\text { Harvested } \\
\text { spinach } \\
\text { leaves }\end{array}$ & $\begin{array}{l}\text { Soil treated } \\
\text { with MIC of } \\
\text { OB Extract }\end{array}$ & $\begin{array}{c}\text { Harvested } \\
\text { spinach } \\
\text { leaves }\end{array}$ & $\begin{array}{c}\text { Soil } \\
\text { without } \\
\text { treatment }\end{array}$ & $\begin{array}{c}\text { Harvested } \\
\text { spinach } \\
\text { leaves }\end{array}$ \\
\hline 0 day & SD & - & SD & - & SD & - & SD & 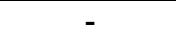 \\
\hline $14 \mathrm{~d}$ & SD & SND & SD & SD & S & SND & SD & SD \\
\hline 28 day & SD & SND & SD & SD & SD & SND & SD & SD \\
\hline 42 days & SND & SND & SD & SD & SD & SND & SD & SD \\
\hline 56 days & SND & SND & SD & SD & SND & SND & SD & SD \\
\hline
\end{tabular}

These results indicate that Salmonella $s p$. in set -1 can not contaminate the spinach plant in presence of $\mathrm{OB}$ extracts. On the treatment of soil with OB extracts host- parasitic interaction inhibited and along with this as their growth is inhibited they were not able to form biofilms so Salmonella sp. can not contaminate spinach plant though they were found viable in the soil. It is also observed even after 56 days of the soil treatment effect of $O B$ extract is effective against Salmonella sp. On the treatment with MIC concentration of $\mathrm{OB}$ extract to the soil of plot-1, it was observed that Salmonella sp. can not contaminate spinach plant in presence of $\mathrm{OB}$ extract even after 56 days of exposure. Periodically soil, water, and spinach leaf sample were taken and analysed for contamination of Salmonella sp. from plot-1 and plot- 2. from plot-

\section{REFERENCES}

Al-Hadidy Y.I.,Yaseen, S. S., Saleh G. M.,(2019) The Inhibitory Effect of some Plant Extracts on some Pathogenic Bacteria, Tikrit Journal of Pure Science,24(1),6269.

Bassolé, I.H.N., Meda, A., Bayala, B., Tirogo, S., Franz, C., Novak, J., Nebié, R.C. and Dicko, M.H. (2010) Composition and Antimicrobial Activities of Lippia multiflora
2 viable Salmonella $s p$. was recovered from the soil on each periodic detection and spinach leaves both, whereas from the plot- 1 viable Salmonella $s p$. was recovered only from soil, which is treated with MIC of OB extract (Table 4). These results indicate that Salmonella $s p$. in plot- 1 can not contaminate the spinach plant in presence of $\mathrm{OB}$ extracts even after 56 days of exposure.

From the above experiments, it can be concluded that MIC $(125 \mu \mathrm{l} / \mathrm{mL})$ of OB extract can successfully treat the soil for preventing contamination of Salmonella $s p$. to spinach plants. OB plant can be used as a preventive measure to overcome soil contamination from Salmonella sp. which may lead to improvements in the health of salad vegetable crops.

Moldenke, Menthax piperita L. and Ocimum basilicum L. Essential Oils and Their Major Monoterpene Alcohols Alone and in Combination. Molecules 15(11): 7825-7839.

Dastouri, M. R., Fakhimzadeh, K., Shayeg, J., Dolgari-Sharaf, J., Valilou, M. R., \& Maheri-Sis, N. (2008) Evaluating Antibacterial Activity of the Iranian Honey 
Through MIC Method on Some Dermal and Intestinal Pathogenic Bacteria. Journal of animal and veterinary advances 7(4): 409-412.

Hassanpouraghdam, M.B., Hassani, A. and Shalamzari, M.S. (2010) Menthone and estragole rich essential oil of cultivated Ocimum basilicum L. from Northwest Iran. CHEMIJA 21(1): 59-62.

Hussain, A.I., Anwar, F., Sherazi, S.T.H., Przybylski, R. (2008) Chemical composition, antioxidant and antimicrobial activities of basil (Ocimum basilicum) essential oils depends on seasonal variations, Food Chemistry, 108 (3): 986-995.

Kisluk, G., and Yaron, S. (2012) Presence and persistence of Salmonella enterica serotype Typhimurium in the phyllosphere and rhizosphere of sprayirrigated parsley. Applied and Environmental Microbiology 78(11): 4030-4036.

Maulidah, E., Thuraidah, A., Lutpiatina, L.(2021) Bactericidal Potential of Extract Citrus Hystrix D.C.Leaf Powder on Staphylococcus aureus and Salmonella typhi. Jurnal Skala Kesehatan,12(1):1-7.

Mostafa, A.A., Abdulaziz, A. A., Almaary, K. S., Dawoud, T. M., Sholkamy, E. N., Bakri, M. M. (2018) Antimicrobial activity of some plant extracts against bacterial strains causing food poisoning diseases, Saudi Journal of Biological Sciences 25(1): 361-366.
Mritunjay, S. K. ,Kumar, V.,(2017) A study on prevalence of microbial contamination on the surface of raw salad vegetables, 3 Biotech 7(13):1-9.

Politeo, O., Jukic, M., Milos, M. (2007). Chemical composition and antioxidant capacity of free volatile aglycones from basil (Ocimum basilicum L.) compared with its essential oil. Food Chemistry 101(1): 379- 385.

Rattanachaikunsopon P. and Phumkhachorn P.(2010) Antimicrobial Activity of Basil (Ocimum basilicum) Oil against Salmonella Enteritidis in Vitro and in Food, Bioscience, Biotechnology, and Biochemistry 76(6): 1200-1204.

Schikora, A., Carreri, A., Charpentier, E., Hirt, H., (2008) The Dark Side of the Salad: Salmonella typhimurium Overcomes the Innate Immune Response of Arabidopsis thaliana and Shows an Endopathogenic Lifestyle. PLoS One 3(5): e2279. https://doi.org/10.1371/journal.pone.0002 279

Wannissorn, B., Jarikasem, S., Siriwangchai, T., Thubthimthed, S. (2005). Antibacterial properties of essential oils from Thai medicinal plants. Fitoterapia,76(2): 233236.

Zheng, J., Allard, S., Reynolds, S., Millner, P., Arce, G., Blodgett, R.J., and Brown, E.W. (2013) Colonization and internalization of Salmonella enterica in tomato plants. Applied and Environmental Microbiology 79(8),:2494-2502. 